\title{
Conditional perfection: The truth and the whole truth *
}

\author{
Elena Herburger \\ Georgetown University
}

\begin{abstract}
Conditional Perfection is argued to arise when a sentence is silently conjoined with an exhaustivized version of the same string. The proposed account, the "whole truth theory', is argued to not only capture Conditional Perfection but to also extend to upper-bounding inferences and exhaustive answers. A crucial piece of the analysis is the independently supported claim that bare conditionals are ambiguous between universal and existential readings.
\end{abstract}

Keywords: Conditional Perfection, negative quantifiers, only, upper-bounding inferences, scalar implicature, exhaustive answers, CEM, homogeneity of bare plurals.

\section{Conditional Perfection}

Conditionals are often taken to express necessary conditions in addition to sufficient ones, a phenomenon known as 'Conditional Perfection'. On a 'perfected' reading, if $p, q$ has the force of a biconditional iff $p, q$, rendering the following (a) sentences equivalent to their (b) counterparts:

(1) a. If you mow the lawn I'll give you $\$ 50$. (cf. Geis \& Zwicky 1971)

b. If and only if you mow the lawn I'll give you $\$ 50$.

a. If you work hard you'll succeed.

b. If and only if you work hard you'll succeed.

Though Conditional Perfection is common, it is, as Lilje (1972)'s (3a) shows, by no means obligatory; (3a) is not taken to mean that the relevant cactus is not an Astrophytum if and only if it grows native to Idaho. Nor does (3b) preclude that taking a vaporetto boat will also reveal what the famous Venetian waterway looks like:

* I am grateful for the helpful feedback I have gotten from Wayne Davis, Larry Horn, Simon Mauck, Tim McCormick, Paul Portner, Barry Schein and members of the audience at SALT 25. Part of the research for this project was supported by NSF Grant \#1053038. 
(3) a. If this cactus grows native to Idaho, then it's not an Astrophytum.

b. If you look at this Canaletto painting you'll get a good idea of what the Canal Grande looks like.

And even when present, Conditional Perfection can be cancelled:

(4) If you work hard you'll succeed. And if you're lucky, you'll succeed as well.

All of this suggests that Conditional Perfection is not tied directly to the semantics of conditionals but is rather a pragmatic phenomenon. ${ }^{1}$

Various proposals have sought to analyze Conditional Perfection in pragmatic terms, and many, if not most of them draw a parallel to upper-bounding inferences (e.g., van der Auwera 1997, Cornulier 1983, Ducrot 1969, Horn 1972, Matsumoto 1995). The similarities between Conditional Perfection and upper-bounding inferences are indeed striking. Like Conditional Perfection, upper-bounding inferences can be lacking, as is the case in understatement:

a. John had a few drinks.

b. Mary got a little upset.

And like Conditional Perfection, upper-bounding inferences can be cancelled:

(6) a. Ben ate some of the biscotti.

b. Ben ate some of the biscotti. In fact, he ate all of them.

Given the affinity between Conditional Perfection and upper-bounding inferences, it is tempting to explain Conditional Perfection as a scalar implicature (SI), the primary means of analyzing upper-bounding inferences. It has, however, proven difficult to do this on the standard neo-Gricean approach, and, as I show, difficulties also persist on the new 'grammatical' approach to SI. I argue that though Conditional Perfection cannot be reduced to SI, upper-bounding inferences and Conditional Perfection are indeed related; I propose a unified account of both that also extends to exhaustive answers, what I call the 'whole truth' theory.

1 Note also that so-called biscuit conditionals cannot be perfected, and neither can even if conditionals, (e.g., Horn 2000):

(i) (a) There are biscuits on the sideboard if you want some.

(b) If you're thirsty, there's beer in the fridge.

(ii) (Even) if the U.S. halts the bombing, North Vietnam will (still) not agree to negotiate.

One thing biscuit and even if conditionals have in common is that their consequents are taken to hold true regardless of whether the antecedent is true or not. It therefore makes sense that it should not be felicitous to 'perfect' them; if the consequent is true regardless of whether the antecedent is, the antecedent can hardly be taken to express a necessary condition for the truth of the consequent. 


\section{Trying to derive Conditional Perfection as SI, neo-Gricean manner}

On the standard neo-Gricean account upper-bounding inferences are derived as SIs by negating alternative sentences appealing to the Maxim of Quantity and a subsequent 'epistemic step' from 'not believing that p' to 'believing that not p' (e.g., Grice 1989). The alternatives are like the original except there is a semantically stronger expression in place of the original scalar expression (e.g., Horn 1972):
a. Ben ate some of the biscotti.
Sentence itself
b. Ben ate all of the biscotti.
Stronger alternative
c. It is not the
the biscotti.

Unfortunately, a neo-Gricean account of SI does not easily extend to Conditional Perfection. One alternative to if that comes to mind is iff. But though iff $p q$ is stronger than if $p q$, iff is not a real lexical item and, moreover, the negation of iff $p$, $q$ does not derive Conditional Perfection but its opposite (Atlas \& Levinson 1981):
a. If you work hard you succeed.
Sentence itself
b. If and only
Stronger alternative
It is not the case that if and only if Negation of stronger alternative you work hard you succeed.

An 'unconditional' alternative, where the alternative to if $p q$ is not iff $p q$ but if $p$ or not $p$, is less obviously wrong (cf. van der Auwera 1997, Matsumoto 1995):
a. If $p q$.
Sentence itself
b. If $p$ or not $p q$
Stronger alternative
c. The following is not the case: if $p$ or not $p q$.

But it still raises issues. One is of a conceptual sort: if $p$ or not $p$ seems a strange alternative to if $p$ (Horn 2000). The second difficulty is of an empirical nature (von Fintel 2001). (9c) together with (9a) amounts to: It is not the case that if not $p q$. Conditional Perfection now only follows if it is not the case that if not $p q$ is equivalent to if not $p$ not $q$. This, however, would require an analysis of conditionals where the negation of an entire conditional is equivalent to the negation of its consequent, in other words an analysis that supports the Conditional Excluded 
Middle (CEM). But of course the standard 'universal' or '(variably) strict' analysis of bare conditionals, given in (10) and (11), does not have this property, cf. (12): ${ }^{2}$

(10) Universal analysis of conditionals:

If $p q$ is true exactly when all $p$-cases are $q$-cases.

(Wallis 1687, Sommers 1982)

(11) (Variably) strict conditional:

a. If $p q$ is true exactly when all $p$-worlds are $q$-worlds. (Lewis 1918)

b. If $p q$ is true exactly when all closest $p$-worlds are $q$-worlds. (Lewis 1973)

(12) Lack of CEM of universal/strict analyses of conditionals: $\neg[\forall x:(p-\operatorname{case}(x)] q$-case $(x) \nLeftarrow[\forall x:(p$-case $(x)] \neg q$-case $(x)$

In sum, if the antecedents of bare conditionals have, as is standardly assumed, universal force, then, all scale issues aside, appealing to an unconditional stronger alternative to if $p q$, if $p$ or not $p q$, does not derive Conditional Perfection as an SI.

\section{Conditional Perfection as an Informativeness or $\mathbf{R}$-based inference}

In view of the problem posed by the iff alternative to if, Atlas \& Levinson (1981) propose to derive Conditional Perfection (along with other inferences) not as a Quantity or Q-based inference but as an inference from a Principle of Informativeness. This principle invites the hearer to infer a contextually implicit 'best', i.e. semantically strongest interpretation, over and above what is actually said. In an instance of Conditional Perfection the 'best' alternative is said to be the perfected one. But, one may ask, why does the unconditional alternative, which is also semantically stronger, not count as the 'best' interpretation instead? Without a specific account of where the 'better' alternatives come from, this account seems incomplete. ${ }^{3}$

2 While the variably strict conditional analysis in Lewis 1973 does not support CEM, the analysis which it is a response to, that in Stalnaker 1968, does. Since on Stalnaker's analysis a conditional is said to be true exactly when in the single closest possible world where the antecedent is true the consequent is true also, it is not the case that if $p q$ comes out as equivalent to if $p$ then not $q$. Lewis (1973) objects to this account on grounds that there is not always a single closest possible world where the antecedent is true (cf. If this line were over one inch long..., for which for any close world that it is true in there will be another closer one, and If Bizet and Verdi were compatriots..., for which presumably the worlds were both composers are French or both are Italian are tied in closeness). Another argument that Lewis adduces against Stalnaker's proposal is that it conflates the difference between would and might conditionals. Both arguments are addressed in Stalnaker 1981.

3 This is a version of the 'symmetry problem' discussed in the literature on scalar implicature, see, e.g., Chierchia, Fox \& Spector 2012. 
Like Atlas \& Levinson (1981), Horn (2000) also analyzes Conditional Perfection as an instance where someone means more than they say but where this does not follow from Grice's Maxim of Quantity (Q-based inference). Rather than appealing to a Principle of Informativeness, he opts for an R-based implicature. Analogous to how I was able to solve the problem $\mathrm{R}$-implicates that the speaker solved it, if is said to generally be understood as R-implicating the stronger if and only if. But, though intriguing, the parallel seems less than perfect in that regular R-based inferences seem more lexicalized and and less contextually dependent than Conditional Perfection.

Evidently, Conditional Perfection is felicitous in certain contexts and not in others, and it seems reasonable to say that pragmatic theory is in charge of explaining this. It is a separate question, I believe, how exactly Conditional Perfection comes about in those instances where it is pragmatically felicitous. Neither the Principle of Informativeness nor a reduction to an R-based inference seems to fully explain that, leaving one wondering if the generation of Conditional Perfection is not somehow related to that of upper bounding inferences after all. In what follows I consider two more options. One is to employ the grammatical account of SI and see if it extends to Conditional Perfection; I argue it does not. The other is to explore a new account of upper-bounding inferences, one that also encompasses Conditional Perfection, and the exhaustiveness of answers to questions. This is the 'whole truth' theory.

\section{Can we derive Conditional Perfection on a grammatical account of SI?}

Whereas the standard neo-Gricean account of upper-bounding inferences has as its driving force the Cooperative Principle, which is thought to guide not only conversation but human cooperation more generally, on the more recent grammatical approach to upper-bounding inferences as SIs they are attributed directly to grammar:

(13) Grammatical account of SI:

$\mathrm{SI}$ is derived by embedding (part of) $\mathrm{S}$ under $O / E x h$.

(e.g., Chierchia et al. 2012).

O/Exh can be thought of as a Rooth-style propositional operator, as in (14) (cf. Rooth 1985), or, alternatively, O/Exh can be defined over sentences, as in (15) (cf. Fox \& Katzir 2011).

$$
\begin{aligned}
& \left.[[O / E x h]]\left(A_{<s t>}\right)\left(p_{<s t>}\right)(w) \Leftrightarrow p(w) \wedge \forall q(q \in N W(p, A)) \rightarrow \neg q(w)\right) \\
& N W(p, A)=q \in A: p \text { does not entail } q(\text { Fox 2007) } \\
& {[[O / E x h S]]=1 \text { iff }[[S]]=1 \wedge \forall S^{\prime}\left(S^{\prime} \in N W(S, A)\right) \rightarrow\left[\left[S^{\prime}\right]\right]=0}
\end{aligned}
$$

The non-weaker alternatives that are negated by $E x h / O$ are given by scalar items, which behave as if they were inherently focused (cf. Krifka 1995, Fox \& Katzir 
2011). Given the universal analysis of bare conditionals in (10)-(11), a 'grammatical' approach to Conditional Perfection would amount to $O / E x h$ if $p q$. The alternatives are signaled by focus on the scalar element, for example hard in (2a):

a. $p$ : If you work HARD you succeed.

b. $p^{\prime}$ : If you work LITTLE you succeed.

c. $p^{\prime \prime}$ : If you DON'T WORK AT ALL you succeed.

Though the grammatical theory's O/Exh is in both instances fashioned after the overt only there remains a difference between the two, namely that under $E x h / O$ the prejacent is fully asserted, which in fact captures that the prejacent under $O / E x h$ is the basic, non-strenghthened meaning of the sentence, whereas the prejacent of only expresses something more akin to a presupposition or something more pragmatically backgrounded (see below).

Does this approach capture Conditional Perfection? Because the conditional prejacent has universal force $O / E x h$ if $p q$ would indeed capture that perfected conditionals express sufficient conditions: (2a) would be predicted to entail a universally quantified prejacent 'All cases where you work hard are cases where you succeed'. Unfortunately, though, the very same universal force of the conditional prejacent that would capture the sufficient condition part would mean that $O / E x h$ if $p q$ would fail to capture that perfected conditionals also express necessary conditions: If $p^{\prime}$ is a relevant alternative to $p$, what is negated by $O / E x h$ is again a universally quantified sentence:

$$
\neg\left[\left[\forall x: p^{\prime}-\operatorname{case}(x)\right] q \text {-case }(x)\right]
$$

When applied to (2a), (17) just excludes that all cases of working little, etc. are cases where you succeed. This, as we saw, is too weak to capture that (2a) rules out that any instances of not working hard lead to success.

\section{The whole truth theory}

In light of the difficulties of deriving Conditional Perfection as a neo-Gricean or 'grammatical' SI, I would like to explore a different proposal (though one that is clearly inpired by these accounts):

(18) The whole truth theory: (1st version)

Conditional Perfection and upper-bounding inferences arise as logical entailments when a sentence $S$ is silently conjoined with enly $S$, resulting in the conjunction $S$ and only $S$. $S$ and only $S$ is then taken to express 'the truth and the whole truth'. If no upper-bounding inference or Conditional Perfection is intended, the and only $S$ conjunct is absent. Whether Conditional Perfection or an upper-bounding inference is intended is a pragmatic matter. 
On the whole truth theory the perfected reading of (2a) follows from the conjunction in (19a) and the upper-bounding inference of (7a) derives, in parallel fashion, from the conjunction in (19b). Since in both instances only the first conjunct is pronounced, an unstrengthened sentence sounds the same as a strengthened one; it is the pragmatic context which helps the hearer figure out which interpretation is intended.

a. If you work HARD you succeed and only if you work HARD-do you succeed.

b. Ben ate SOME of the biscotti and Ben only ate SOME of the biscotti.

In (19a) the first conjunct if you work HARD you succeed has the meaning it normally has; it expresses that hard work is a sufficient condition for success. And just like its overt counterpart, the second, silent conjunct and-only if you-work HARD do you succeed expresses what it normally expresses, namely that hard work is a necessary condition for success. Conditional Perfection follows. But how exactly does Only if you work hard do you succeed come to mean what it means? This in fact constitutes a semantic puzzle, to which I now turn, before then returning to Conditional Perfection.

\section{The semantics of only if conditionals}

\subsection{The challenge}

Only if conditionals like those in (20) pose a challenge because combining the (variably) strict conditional analysis of bare conditionals, repeated in (21), with a semantics for only, for example (22), does not give us their meaning.

a. Only if you work hard do you succeed.

b. Doug only walks the dog when Sid's not around.

(21) Universal analysis of conditionals:

If $p q$ is true exactly when all $p$-cases are $q$-cases.

$$
\begin{aligned}
& {[[\text { only } S]]=1 \text { iff }[[S]]=1 \wedge \forall S^{\prime}\left(S^{\prime} \in N W(S, A)\right) \rightarrow[[S]]=0} \\
& S \text { expresses backgrounded information } 4
\end{aligned}
$$

4 There exists a long-standing debate (recounted in e.g., Horn 2002) as to whether (part of) the prejacent of only is presupposed ('assymetricalists') or whether it is entailed ('symmertricalist'). Both views have their justification, and are, in fact, not incompatible: we can say that the prejacent is entailed as part of the truth-conditional meaning but in a pragmatically backgrounded or 'assertorically inert' manner, (e.g., Atlas 1993, Herburger 2000, Horn 2002). Support comes from Atlas (1993)'s point that I love only you is not a mere presupposition failure if the speaker does not love the addressee. 
One issue we encounter is that only if conditionals express necessary conditions. Just as with conditionals under $O / E x h$, on the universal analysis conditionals under only are merely predicted to rule out that all alternative cases are $q$-cases. But (20a), for example, does not just deny that all cases of not working hard lead to success but says that none of them do. In other words, assuming a universal prejacent leads to an analysis that does not capture the exclusionary force that we observe. The second issue is this: Because the conditional prejacent is, by hypothesis, universally quantified, (20a) is predicted to entail in a backgrounded manner that hard work guarantees success. But only if conditionals do not really suggest in any way that the antecedent expresses sufficient conditions for the truth of the consequent. If they did, they would have a force similar to that of bi-conditionals. That they do not is already noted by McCawley (1974) and becomes evident when we compare the coherent (23a) with the contradictory (23b):

a. Only if you work hard do you succeed but hard work does not guarantee success. coherent

b. If and only if you work hard you succeed but hard work does not guarantee success. contradictory

One can try to solve the problem regarding the exclusionary force by appealing to CEM (von Fintel 1997$)^{5}$ but this move will not solve the problem with the overly strong presupposition/backgrounded entailment generated by the conditional prejacent of only illustrated in (23); this will persist as long as we assume that the bare conditional prejacent of only has universal force.

\subsection{The duality of conditionals}

The meaning of only if conditionals becomes less of a puzzle if we assume that bare conditionals are actually ambiguous (Herburger 2015).

Conditional Duality:

Normally, bare conditionals have universal force but in downward entailing contexts, bare conditionals have, all things being equal, existential force.

5 In order to keep the advantages of the Lewis style variably strict conditional and, at the same time, have CEM to deal with the exclusionary force of only if conditionals, von Fintel (1997) translates if-clauses as generic rather than universal quantifiers. He then appeals to the 'homogeneity' of generic quantifiers under negation (see the observation in Fodor 1970 and Löbner 2000 that Women don't like doing dishes, e.g., is a generic claim about women's dislikes, see also discussion of this below) to derive CEM and, with it, the exclusionary force of only if conditionals. Since, however, generic quantification is somewhat weaker than universal quantification, this analysis would not seem to derive the full exclusionary force of only if conditionals (Cohen 2004). 
Conditional perfection

It should be noted at this point that Dekker (2001) posits an operator (*) for conditionals in downward entailing contexts. His * operator turns a material conditional into a conjunction:

$$
[\lambda q \cdot p \rightarrow q]^{*}=\lambda q \cdot \neg[p \rightarrow \neg q]=\lambda q \cdot[p \wedge q]
$$

Obviously, I do not posit an operator, but rather an ambiguity. Nor do I assume that bare conditionals have the semantics of the material conditional, or that the truthconditions of if in downward entailing contexts can really be translated as conjunction (see appendix A). That said, by recognizing duality for bare conditionals, my analysis is clearly similar in spirit to that in Dekker 2001, see also Higginbotham 1986, 2003, appendix A.

Conditional Duality results in the conditional prejacent of only in (20a) being interpreted existentially as in (26). Since the alternatives ruled out by only all have the form in (27), the exclusionary force of only if conditionals now follows directly from the semantics of existential quantification under negation; (20a) amounts to something like (28). ${ }^{6}$

$[\exists x$ :You-work-hard-case $(x)]$ You-succeed-case(x)

$\neg\left[\exists x: p^{\prime}-\operatorname{case}(x)\right] q-\operatorname{case}(x)$

(28) Assertion of (20a):

It is not the case that in some (any) cases where you work a little you succeed. It is not the case that in some (any) cases where you work when you feel like it you succeed. Etc.

The backgrounded entailment of only if conditionals also fall into place. The overly strong entailment generated by the strict conditional is now gone, and the distinction between only if conditionals and bi-conditionals is preserved. Moreover, from the existential force of the conditional and the meaning of only it follows that (20a) entails that at least in some cases hard work may lead to success. This explains that (20a) can be used to encourage someone to work hard, the argument being that hard work increases the chances for success, even if it doesn't guarantee it. Similarly, (29)

6 The assumption here is that only creates a downward entailing context. This has to be relativized to its negative component, excluding the pragmatically backgrouded prejacent (e.g., von Fintel 1999, Horn 2002). Thus, the inference from (ia) to (ib) goes through provided we independently know that someone went to Isla Margarita, off the coast of mainland Venezuela. Other instances where 'assertorically inert' material has to be abstracted away from are discussed in Horn 2002.

(i) a. Only Juanita went to Venezuela.

b. Only Juanita went to Isla Margarita. 
is predicted to be misleading because it entails that there is a possibility of drinking kale juice and living to be 130; as far as we know that is simply false because, no matter what juice you consume, the odds of living to 130 are zero:

(29) Only if you drink kale juice do you live to be 130.

McCawley (1974) and von Fintel (1997) already toyed with the idea that conditionals under only have existential rather than universal force, but, in the end, rejected this possibility because it seemed stipulative. But there is some independent support.

\subsection{Negative quantifiers and Conditional Duality}

Support for Conditional Duality comes from conditionals under negative quantifiers, which pose a long-standing problem (Higginbotham 1986, 2003; Dekker 2001; von Fintel 1998; von Fintel \& Iatridou 2002; Leslie 2009, a.o.) that can be summarized as follows: Translating the conditional as a strict conditional works well when the conditional is embedded under a universal quantifier, but not when in the scope of a negative quantifier. The issue is that (31b) says that for no student do all instances of goofing off result in success when (30b) in fact means that for no student do any instances of goofing off result in success.

(30) a. Every student will succeed if he works hard.

b. No student will succeed if he goofs off. (Higginbotham 1986)
a. $[$ Every $x: \operatorname{Student}(x)][\forall y: \operatorname{Work}-\operatorname{hard}(x$, at $y)] \operatorname{Succeed}(x$, at $y)$
b. $[\operatorname{No} x: \operatorname{Student}(x)][\forall y: \operatorname{Goof}-\operatorname{off}(x$, at $y)] \operatorname{Succeed}(x$, at $y)$

Matters improve once we assume Conditional Duality (Herburger 2015). While (31a) retains a logical form where the conditional has universal force, (30b) now has a logical form where the conditional has mere existential force. This captures that the conditional excludes that any goofing off is compatible with success:

$$
[\text { No } x: \operatorname{Student}(x)][\exists y: \operatorname{Goof-off}(x \text {, at } y)] \operatorname{Succeed}(x \text {, at } y)
$$

The analysis works straightforwardly (for other proposals see appendix A), and, importantly, it provides independent support for the proposed duality analysis of conditionals under only. Given that negation creates the negative environment par excellence we would expect that negated conditionals provide a further argument for Conditional Duality. Some arguments for this are briefly discussed in appendix B. 
Conditional perfection

\section{Parallels between bare conditionals and bare plurals}

Having argued for the duality of bare conditionals, I would now also like to briefly consider bare plurals. As is well-known, bare plurals exhibit generic or (quasi)universal readings alongside their existential readings. Strikingly, however, bare plurals that normally have a (quasi)-universal reading because they combine with an individual level predicate show an existential reading when embedded under only. As already noted in McCawley 1974, (33b) merely rules out that non-Southerners voted for Humphrey but does not entail that Southerners in general voted for Humphrey. Similarly, unlike in (34a) no genericity seems to be present in (34b).

\section{a. Southerners voted for Humphrey. \\ b. Only SOUTHERNERS voted for Humphrey.}

a. Men smoke cigars.

b. Only MEN smoke cigars.

The lack of (quasi-)universal force of SOUTHERNERS in (33b) and MEN in (34b) suggests we should extend the duality thesis (Herburger 2015):

Duality of bare conditionals and bare plurals:

Normally, bare conditionals and bare plurals that combine with individual level predicates have universal force, but in downward entailing contexts they have, all things being equal, existential force.

The duality of bare plurals may, in addition to explaining their meaning under only, also help us make sense of the 'homogeneity' that bare plurals are known to show under negation (e.g., Fodor 1970, Löbner 2000, von Fintel 1997); we can now say that (36), for example, amounts to saying that Austrians generally are not familiar with the The Sound of Music because even though the bare plural Austrians combines with an individual level predicate, it translates as an existential quantifier as it appears in a negative context, as shown in (37): ${ }^{7}$

Austrians don't know The Sound of Music.

$$
\begin{aligned}
& \neg[\exists X: \exists x(X(x) \wedge \forall y(X(y) \rightarrow \text { Austrians }(y)))] \exists z(X(z) \wedge \text { Knows-The-Sound- } \\
& \text { of-Music }(z))
\end{aligned}
$$

7 A similar idea is already discussed in by Krifka (1996), who argues that plural definite descriptions are ambiguous between universal and existential readings. This, together with the 'strongest meaning hypothesis' favors, barring separate pragmatic factors, the existential reading in downward entailing contexts but the universal one elsewhere. For a different account of the homogeneity of plural definite descriptions see, however, Schein 2015. While I posit existential/universal ambiguity for bare plurals and bare conditionals and observe that the existential reading often appears in downward entailing contexts and the universal reading elsewhere I do not want to commit at this point to anything beyond that. I have not explored yet whether this distribution can be attributed to the strongest meaning hypothesis or whether it is due to something else. 


\section{Extension: The whole truth theory and exhaustive answers to questions}

If we now turn to answers we find that, curiously, bare plurals used as exhaustive answers exhibit a universal reading:

A: Who smokes cigars?

B: MEN do./MEN smoke cigars.

If the exhaustiveness of answers were merely derived by embedding the answer under O/Exh, (38B) should pattern with (34b) and it should lack the (quasi-)universal force that it seems to show on top of the exhaustive force. The universal force of (38B) suggests instead that it is interpreted along the lines of (39):

\section{MEN smoke cigars and only MEN smoke cigars.}

More generally, the interpretation of (38) suggests the whole truth theory should be extended to exhaustive answers:

(40) The whole truth theory: (2nd version)

Conditional Perfection, upper-bounding inferences and the exhaustiveness of answers (to explicit or implicit questions) arise as logical entailments when a sentence $S$ is silently conjoined with and-only $S$. $S$ and only $S$ is taken to express 'the truth and the whole truth'. If no upper-bounding inference, Conditional Perfection or exhaustiveness is intended, the and only $S$ conjunct is absent. Whether Conditional Perfection, an upper-bounding inference or an exhaustive reading of an answer is intended is a pragmatic matter.

Given (40), we now expect if-clauses that are used as exhaustive answers to be subtly different in meaning from only if-answers. Consider (41):
A: Do you ever go swimming in the morning?
B: If I'm on vacation.
B': Only if I'm on vacation.

(41B') entails that you don't swim when not on vacation, while (41B) only entails it when read exhaustively. What is of particular interest is that when read exhaustively, (41B) is easily taken to imply that you swim regularly when on vacation, while (41B') tends to mean that there are some morning swims when on vacation (and only then). This suggests that when (41B) is an exhaustive answer it is interpreted on the $S$ and only $S$ schema, as 'I go swimming in the morning when I'm on vacation and I only go swimming in the morning when I'm on vacation'. Thus (41B) in the end has the logical form in (42): The first conjunct represents the meaning of the first instance of $S$, which since it is outside of a downward entailing context involves universal quantification, helping capture the quasi-universal or 
generic force we observe in (41B) in contradistinction with (34b). The second and the third conjuncts represent the meaning of and only $S$, with the second conjunct asserting (in a backgrouded manner) the existentially quantified prejacent and the third conjunct negating alternatives, which are, crucially, existentially quantified, thus capturing the exhaustiveness of the answer.

$$
\begin{aligned}
& {[[\forall x: R(x) \wedge \operatorname{I'm-on-vacation}(x)] \text { Go-Swimming }(x)]} \\
& \wedge[[\exists y: R(y) \wedge \text { I'm-on-vacation(y)] Go-Swimming }(y)] \\
& \wedge \neg[[\exists z: R(z) \wedge \text { I'm-working }(\mathrm{z})] \text { Go-Swimming }(z)] \wedge \ldots
\end{aligned}
$$

A connection between Conditional Perfection and the exhaustiveness of answers has not gone unnoticed (e.g., Cornulier 1983; Groenendijk \& Stokhof 1984). I argue the exhaustiveness of answers is not due to simple embedding under an exhaustifying operator but follows from the $S$ and only $S$ schema.

\section{Implementation: If-clauses as plural definite descriptions}

\subsection{The basic analysis of conditionals}

To keep matters simple I have employed an analysis of conditionals according to which if-clauses denote quantifiers over individual cases. But there are reasons to think that if-clauses should be analyzed as topic-like plural definite descriptions of possible events or situations and that adverbs of quantification should interpreted in-situ as taking scope over the consequent (Schein 2003, cf. also Schlenker 2004; Bhatt \& Pancheva 2006). On this more detailed analysis, (43) has the logical form in (44), saying 'The possible events where you work hard are such that (a) for most among them there are related events (b) all of which are events where you succeed (c).'

(43) If you work hard you usually succeed.

$$
\begin{aligned}
& {[\imath X: \forall e(X(e) \leftrightarrow \text { you-work-hard }(e))]} \\
& {\left[\operatorname{Most} e^{\prime}: X\left(e^{\prime}\right)\right]\left[\exists X^{\prime}: \exists e^{\prime \prime}\left(X^{\prime}\left(e^{\prime \prime}\right) \wedge \forall e^{\prime}\left(X^{\prime}\left(e^{\prime \prime}\right) \rightarrow R\left(e^{\prime \prime}, e^{\prime}\right)\right)\right)\right]} \\
& {\left[\forall e^{\prime \prime \prime}: X^{\prime}\left(e^{\prime \prime \prime}\right)\right] \text { you-succeed }\left(e^{\prime \prime \prime}\right)}
\end{aligned}
$$

On this account, the word if clearly has meaning (cf. also Gillies 2010).

$$
[[i f]]=\lambda f_{<e t>} \cdot \lambda g_{<E t>} \cdot[\imath E: \forall e(E(e) \leftrightarrow f(e)=1] g(E)=1
$$

Following Schein (2003), I further assume that the non-monotonicity of conditionals (Stalnaker 1968; Lewis 1973) stems from a tacit ceteris paribus clause which functions like a stacked antecedent and which in the example at hand would be between (b) and (c), giving us (46) as the full logical form for (43). Important though this is for the overall analysis of conditionals, due to limitations of space I abstract away from the ceteris paribus clause in the remainder of the paper. 


$$
\begin{aligned}
& {[\imath X: \forall e(X(e) \leftrightarrow \text { you-work-hard }(e))]} \\
& {\left[\text { Most } e^{\prime}: X\left(e^{\prime}\right)\right]\left[\exists X^{\prime}: \exists e^{\prime \prime}\left(X^{\prime}\left(e^{\prime \prime}\right) \wedge \forall e^{\prime}\left(X^{\prime}\left(e^{\prime \prime}\right) \rightarrow R\left(e^{\prime \prime}, e^{\prime}\right)\right)\right)\right]} \\
& {\left[\imath E^{\prime \prime}: \forall e^{\prime \prime \prime}: X^{\prime \prime}\left(e^{\prime \prime \prime}\right) \leftrightarrow \text { Ceteris-paribus }\left(e^{\prime \prime \prime}, e^{\prime}\right)\right]} \\
& {\left[\forall e^{\prime \prime \prime}: X^{\prime \prime}\left(e^{\prime \prime \prime}\right)\right] \text { you-succeed }\left(e^{\prime \prime \prime}\right)}
\end{aligned}
$$

If we assume that covert adverbs are interpreted like their overt counterparts the duality of bare conditionals now amounts to an ambiguity of the tacit adverb quantifying over the consequent. Thus (47), which represents the universal reading, has a universal quantifier beginning the second line. Its existential counterpart is identical except that the quantifier is existential, cf. (48b):

$$
\begin{aligned}
& {[\imath X: \forall e(E(e) \leftrightarrow \text { you-work-hard }(e))]} \\
& {\left[\forall e^{\prime}: E\left(e^{\prime}\right)\right]\left[\exists E^{\prime}: \exists e^{\prime \prime}\left(E^{\prime}\left(e^{\prime \prime}\right) \wedge \forall e^{\prime}\left(E^{\prime}\left(e^{\prime \prime}\right) \rightarrow R\left(e^{\prime \prime}, e^{\prime}\right)\right)\right)\right]} \\
& {\left[\forall e^{\prime \prime \prime}: E^{\prime}\left(e^{\prime \prime \prime}\right)\right] \text { you-succeed }\left(e^{\prime \prime \prime}\right)} \\
& {[\imath X: \forall e(E(e) \leftrightarrow \text { you-work-hard }(e))]} \\
& {\left[\exists e^{\prime}: E\left(e^{\prime}\right)\right]\left[\exists E^{\prime}: \exists e^{\prime \prime}\left(E^{\prime}\left(e^{\prime \prime}\right) \wedge \forall e^{\prime}\left(E^{\prime}\left(e^{\prime \prime}\right) \rightarrow R\left(e^{\prime \prime}, e^{\prime}\right)\right)\right)\right]} \\
& {\left[\forall e^{\prime \prime \prime}: E^{\prime}\left(e^{\prime \prime \prime}\right)\right] \text { you-succeed }\left(e^{\prime \prime \prime}\right)}
\end{aligned}
$$

The ambiguity of the covert adverb recalls that of ever, which in certain contexts can be read universally but in downward entailing contexts is read existentially, having the distribution of an NPI: ${ }^{89}$

a. Ever the optimist, she said that it would work just fine. $\forall$

b. Don't ever try this at home! $\exists$ (NPI)

Given this analysis of conditionals, embedding If you work hard you succeed under only results in the following kind of logical form: 'Among the events where you work hard are ones resulting in success (lines a-c) and it's not the case that among the events where you work little there are events that lead to success, etc. (lines d-f)':

8 Whether any can also be analyzed as ambiguous between a universal and existential reading is of course an obvious but complex question, the discussion of which goes beyond the scope of this paper.

9 Several indigenous languages of the Pacific Northwest have been noted to have modal operators with both universal or existential force. Particularly striking in the present context is the $o$ ' qa suffix in Nez Perce, which according to Deal (2011) is existential in downward entailing contexts but ambiguous elsewhere. Deal attributes this to o'qa being an existential operator that lacks a stronger scale mate. At this point I do not fully understand if there is a relation between this kind of modal adverb and the, in my view, ambiguous tacit adverbial quantifier in bare conditionals, or the ambiguous ever. 
Conditional perfection

$$
\begin{aligned}
& {[[\imath X: \forall e(E(e) \leftrightarrow \text { you-work-hard }(e))]} \\
& {\left[\exists e^{\prime}: E\left(e^{\prime}\right)\right]\left[\exists E^{\prime}: \exists e^{\prime \prime}\left(E^{\prime}\left(e^{\prime \prime}\right) \wedge \forall e^{\prime}\left(E^{\prime}\left(e^{\prime \prime}\right) \rightarrow R\left(e^{\prime \prime}, e^{\prime}\right)\right)\right)\right]} \\
& \left.\left[\forall e^{\prime \prime \prime}: E^{\prime}\left(e^{\prime \prime \prime}\right)\right] \text { you-succeed }\left(e^{\prime \prime \prime}\right)\right] \\
& \wedge \neg[[\imath X: \forall e(E(e) \leftrightarrow \text { you-work-little }(e))] \\
& {\left[\exists e^{\prime}: E\left(e^{\prime}\right)\right]\left[\exists E^{\prime}: \exists e^{\prime \prime}\left(E^{\prime}\left(e^{\prime \prime}\right) \wedge \forall e^{\prime}\left(E^{\prime}\left(e^{\prime \prime}\right) \rightarrow R\left(e^{\prime \prime}, e^{\prime}\right)\right)\right)\right]} \\
& \left.\left[\forall e^{\prime \prime \prime}: E^{\prime}\left(e^{\prime \prime \prime}\right)\right] \text { you-succeed }\left(e^{\prime \prime \prime}\right)\right] \text { etc. }
\end{aligned}
$$

\subsection{Prediction regarding only if and perfected conditionals:}

Turning now to conditionals with overt adverbs, we find that the tacit existential adverb in only if conditionals is but a default and its force is over-ridden by that of an overt adverb if there is one. Depending on the force of the overt adverb, (51) rules out that anything other than hard work always/often/usually/never leads to success. This follows if the conditional embedded under only has the logical form in (52):

Only if you work HARD do you always/often/usually/never succeed.

$$
\begin{aligned}
& {[\imath X: \forall e E(e) \wedge \text { you-work-hard }(e)]} \\
& {\left[\text { All/Many... } e^{\prime}: E\left(e^{\prime}\right)\right]\left[\exists E^{\prime}: \exists E^{\prime \prime}\left[E ^ { \prime } ( e ^ { \prime \prime } ) \wedge \forall e ^ { \prime } \left(E^{\prime}\left(e^{\prime \prime}\right) \rightarrow\right.\right. \text { (b) }\right.} \\
& \left.\left.\left.R\left(e^{\prime \prime}, e^{\prime}\right)\right)\right]\right] \\
& {\left[\forall e^{\prime \prime \prime}: E^{\prime}\left(e^{\prime \prime \prime}\right)\right] \text { you-succeed }\left(e^{\prime \prime \prime}\right)}
\end{aligned}
$$

Since on the present account conditional perfection arises from conjoining a conditional $S$ with a silent exhaustivized version of itself and only $S$ we now expect that just as with only if conditionals, perfected conditionals with overt adverbs should also 'inherit' the force of the overt adverb if there is one. And, indeed, when perfected (53) can be paraphrased as in (54), where the second conjunct is interpreted as in (52). The if-clause denotes necessary and sufficient conditions not for success but, depending on the force of the adverb, necessary and sufficient conditions for inevitable/frequent/likely/non-realized success.

(53) If you work hard you always/often/usually/never succeed.

(54) If you work hard you always/often/usually/never succeed and-only-if you work hard do you always/often/usually/never succeed.

\section{Conclusion}

Bare conditionals show duality between universal and existential readings, with the latter appearing in downward entailing contexts. Bare plurals combining with individual level predicates can be argued to behave similarly and to also show 
existential readings in downward entailing contexts. Conditional Perfection, upperbounding inference and the exhaustiveness of answers all arise when a sentence $S$, expressing 'the truth', is silently conjoined with and only $S$, expressing 'the whole truth'. The whole truth theory is indebted to both the neo-Gricean approach to upper bounding inferences and to the grammatical theory; like the neo-Gricean approach the whole truth theory keeps separate the sentence $(S)$ and its 'implicature' (only $S$ ), and like the grammatical approach it relies on a silent operator, in particular a silent but, in the case of the whole truth theory, otherwise completely synonymous occurrence of the word only.

\section{A Previous accounts of conditionals under negative quantifiers}

I have argued that conditionals under negative quantifiers, like conditionals under only, have only existential force (Herburger 2015). But of course there have been previous accounts of this phenomenon, several of which I'd like to briefly discuss. One approach to conditionals like (30b) or (55a) assigns if in this kind of environment simply the meaning of and (Higginbotham 1986, cf. Dekker 2001). (55a) on this account has the logical form in (55b), which would render it equivalent to (55c):

a. No student will succeed if he or she goofs off.

b. $\neg \exists x(\operatorname{Student}(\mathrm{x}) \wedge$ Goof-off $(\mathrm{x}) \wedge \operatorname{Succeed}(\mathrm{x}))$

c. No student will succeed and goof off.

Conceptually, this approach raises the specter of noncompositionality as if seems to have one meaning in one environment and another in another context (Higginbotham 1986, 2003). ${ }^{10}$ Empirically, it is problematic in that (55a) and (55b)/(55c) are not really equivalent (Leslie 2009): (55a) is falsified by Meadow, for example, who will get a good grade no matter what because her mobster father pressures the teacher. But if Meadow happens to work hard (maybe to spite Dad) she does not actually falsify (55b)/(55c).

Another approach (von Fintel 1998) is to uniformly translate the if-clause as a restrictor, a la Lewis/Kratzer for adverbs and modals, and to analyze (55a) as (56):

No student who goofs off will succeed.

But, Meadow's hard work again causes trouble, making the truth conditions of (55a) and (56) come apart; though she will make (55a) false because Dad has taken

10 My analysis could of course also be faulted with this but I do not think that the meaning changes depending on environment but that we are dealing with an ambiguity, where each reading seems restricted to a particular context. Whether the strongest meaning hypothesis accounts for this distribution or whether it is something else is, admittedly, a question that is relevant but left unanswered. I hope to address it in future research. 
care of her grade, she will not falsify (56) because she does not actually goof off (Higginbotham 2003; von Fintel \& Iatridou 2002; Leslie 2009). ${ }^{11}$

A third approach explains conditionals under negative quantifiers by positing (presupposing) CEM (and decomposition of the negative quantifiers). That such an analysis is possible is noted in Higginbotham (2003), who, however, voices reservations about CEM; not so von Fintel \& Iatridou (2002), who argue for this kind of account:

[No x: Student(x)] [All w: Goof-off(x, in w)] Succeed (x, in w) $\Leftrightarrow$ [All x: Student(x)] $\neg[$ All w: Goof-off(x, in w) $]$ Succeed $(x$, in w $) \Leftrightarrow$ [All x: Student(x)] [All w: Goof-off(x, in w)] $\neg$ Succeed (x, in w) (via CEM)

The problem with CEM is of course that if one assumes a (variable) strict conditional analysis, as von Fintel \& Iatridou (2002) do, CEM is a stipulation.

\section{B Conditional duality and negation}

One reason semanticists have toyed with CEM in the first place is that the negation of a conditional often seems intuitively equivalent to the negation of its consequent. (58 a-c) can all be taken to say that Mary's goofing off will result in failure.
a. It's not true that Mary will succeed if she goofs off.
b. I don't think that Mary will succeed if she goofs off.
c. Mary won't succeed if she goofs off.

As noted in footnote 2 , the analysis given by Stalnaker $(1968,1981)$ supports CEM and thus captures this observation, but at the price of assuming that there is a single closest possible world where the antecedent is true. The variably strict conditional proposed in response in Lewis (1973) does not validate CEM, and, as already noted, if CEM is to be used, it needs to be stipulated (von Fintel 1998; von Fintel \& Iatridou 2002).

Conditional Duality, in contrast, explains the fact without the need for CEM. That the negation of a conditional should seem equivalent to the negation of its consequent is due to the fact that, the identical phonology notwithstanding, we are not dealing with the same conditional as the negated conditional actually has existential force while the non-negated one has universal force. The observed equivalence thus follows from a basic logical equivalence:

$$
\neg[\exists w \text { : Goof-off }(\mathrm{j}, \mathrm{w})] \operatorname{Succeed}(\mathrm{j}, \mathrm{w}) \Leftrightarrow[\forall \mathrm{w}: \operatorname{Goof}-\mathrm{off}(\mathrm{j}, \mathrm{w})] \neg \operatorname{Succeed}(\mathrm{j}, \mathrm{w})
$$

11 A possible solution to save the restrictor theory is to modalize the restrictor, Leslie (2009), cf. Klinedinst (2011) for a critique. 
This account might also help us make sense of instances where a negated conditional does not actually seem equivalent to the negation of its consequent, which run counter to CEM (and which pose problems for account of conditionals that support CEM (Leslie 2009). It seems to me that examples like these arise where the negated conditional denies a previous, strong conditional:

$$
\begin{array}{lc}
\text { A: If a fair coin is flipped it will land heads. } & F \\
\text { B: If a fair coin is flipped it will NOT land heads. } & \text { T }
\end{array}
$$

If a fair coin is flipped it will land tails. $\mathrm{F}$

The diverging truth values of (60B) and (61) show that here the negation of entire conditional is not equivalent to negation of its consequent. This, I speculate, is due to $(60 \mathrm{~B})$ involving a metalinguistic denial negation, with (60B) being a direct contradiction of $(60 \mathrm{~A})$, including its universal quantificational force:

$$
\neg[\forall w:[\text { Ax: Fair-coin(x) }] \text { Flipped(x, w) }] \text { Land-heads(x, w) } \quad \mathrm{T}
$$

In contrast, when uttered in isolation the negated conditional in (62) is interpreted as being existentially quantifed, creating the illusion of CEM:

$$
\text { If a fair coin is flipped it will not land heads. F }
$$

$$
\neg[\exists w:[\text { Ax: Fair-coin(x)] Flipped(x, w) }] \text { Land-heads(x, w) F }
$$

\section{References}

Atlas, Jay D. 1993. The importance of being only: Testing the neo-Gricean versus neo-entailment paradigms. Journal of Semantics 10. 301-318.

Atlas, Jay D. \& Stephen C. Levinson. 1981. It-clefts, informativeness, and logical form. In Peter Cole (ed.), Radical Pragmatics, 1-62. New York: Academic Press.

van der Auwera, Johan. 1997. Pragmatics in the last quarter century: The case of conditional perfection. Journal of Pragmatics 27. 261-274.

Bhatt, Rajesh \& Roumyana Pancheva. 2006. Conditionals. The Blackwell Companion to Syntax 1. 638-687.

Chierchia, Gennaro, Danny Fox \& Benjamin Spector. 2012. Scalar implicature as a grammatical phenomenon. In Claudia Maienborn, Klaus von Heusinger \& Paul Portner (eds.), Semantics: An International Handbook of Natural Language Meaning, vol. III, 2297-2391. Mouton de Gruyter.

Cohen, Ariel. 2004. Existential generics. Linguistics and Philosophy 27(2). 137-168. Cornulier, Benoit de. 1983. If and the presumption of exhaustivity. Journal of Pragmatics 7. 247-249. 
Conditional perfection

Deal, Amy Rose. 2011. Modals without scales. Language 87(3). 559-585.

Dekker, Paul. 2001. On if and only. In Rachel Hastings, Brendan Jackson \& Zsofia Zvolensky (eds.), Proceedings from Semantics and Linguistics Theory (SALT) XI, 114-133. Cornell University.

Ducrot, Oswald. 1969. Présupposés et sous-entendus. Langue Française 30-43.

von Fintel, Kai. 1997. Bare plurals, bare conditionals, and only. Journal of Semantics 14. 1-56.

von Fintel, Kai. 1998. Quantifiers and 'if'-clauses. The Philosophical Quarterly 48(191). 209-214.

von Fintel, Kai. 1999. NPI licensing, Strawson entailment, and context dependency. Journal of Semantics 16(2). 97-148.

von Fintel, Kai. 2001. Conditional strengthening: A study in implicature. Unpublished ms., MIT.

von Fintel, Kai \& Sabine Iatridou. 2002. If and when 'if'-clauses can restrict quantifiers. Unpublished ms.

Fodor, Janet Dean. 1970. The linguistic description of opaque contexts: MIT Doctoral dissertation.

Fox, Danny. 2007. Free choice disjunction and the theory of scalar implicature. In Uli Sauerland \& Penka Stateva (eds.), Presupposition and Implicature in Compositional Semantics, 71-120. New York: Palgrave Macmillan.

Fox, Danny \& Roni Katzir. 2011. On the characteristics of alternatives. Natural Language Semantics 19. 87-107.

Geis, Michael \& Arnold Zwicky. 1971. On invited inferences. Linguistic Inquiry 2. 561-566.

Gillies, Anthony. 2010. Iffiness. Semantics and Pragmatics 3. 1-42.

Grice, H. Paul. 1989. Studies in the Way of Words. Cambridge: Harvard University Press.

Groenendijk, Jeroen \& Martin Stokhof. 1984. Studies in the semantics of question and pragmatics of answers: Amsterdam University Doctoral dissertation.

Herburger, Elena. 2000. What Counts: Focus and Quantification. Cambridge: MIT Press.

Herburger, Elena. 2015. Only if conditionals: if only we understood them. To appear in Sinn und Bedeutung 19.

Higginbotham, James. 1986. Linguistic theory and Davidson's program in semantics. In Ernest LePore (ed.), Truth and interpretation: Perspectives on the Philosophy of Donald Davidson, 29-48. Cambridge: Blackwell.

Higginbotham, James. 2003. Conditionals and compositionality. In John Hawthorne \& Dean Zimmerman (eds.), Language and philosophical linguistics, volume 17: Philosophical Perspectives, 181-194. Oxford: Blackwell.

Horn, Larry. 1972. On the semantic properties of logical operators in English: 
UCLA Doctoral dissertation.

Horn, Larry. 2000. From IF to IFF: Conditional perfection as pragmatic strengthening. Journal of Pragmatics 32. 289-326.

Horn, Larry. 2002. Assertoric inertia and NPI licensing. In Proceedings from the Chicago Linguistics Society, the panels, 55-82.

Klinedinst, Nathan. 2011. Quantified conditionals and conditional excluded middle. Journal of Semantics 28. 149-170.

Krifka, Manfred. 1995. The semantics and pragmatics of polarity items. Linguistic Analysis 25. 209-257.

Krifka, Manfred. 1996. Pragmatic strengthening in plural predications and donkey sentences. In Teresa Galloway \& Justin Spence (eds.), Semantics and Linguistic Theory (SALT) VI Proceedings, vol. 6, 136-153. Ithaca: CLC Publications.

Leslie, Sarah-Jane. 2009. If, unless and quantification. In Robert Stainton \& Christopher Viger (eds.), Compositionality, Context and Semantic Values: Essays in Honour of Ernie Lepore, 3-30. Dordrecht: Springer.

Lewis, Clarence Irving. 1918. A Survey of Symbolic Logic. University of California Press.

Lewis, David. 1973. Counterfactuals. Cambridge: Harvard University Press.

Lilje, Gerald W. 1972. Uninvited inference. Linguistic Inquiry 3. 540-542.

Löbner, Sebastian. 2000. Polarity in natural language: Predication, quantification and negation in particular and characterizing sentences. Linguistics and Philosophy 23. 213-308.

Matsumoto, Yo. 1995. The conversational condition on Horn scales. Linguistics and Philosophy 18. 21-60.

McCawley, James D. 1974. If and only if. Linguistic Inquiry 5. 632-635.

Rooth, Mats. 1985. Association with focus: University of Massachusetts Doctoral dissertation.

Schein, Barry. 2003. Adverbial, descriptive reciprocals. Philosophical Perspectives 17(1). 333-367.

Schein, Barry. 2015. Noughty bits: The subatomic scope of negation. Unpublished ms.

Schlenker, Phillippe. 2004. Conditionals as definite descriptions. Research on Language and Computation 2(3). 427-462.

Sommers, Frederic. 1982. The Logic of Natural Language. Oxford: Clarendon Press.

Stalnaker, Roger. 1968. A theory of conditionals. American Philosophical Quarterly Monograph Series 2. 98-112.

Stalnaker, Roger. 1981. A defense of the conditional excluded middle. In William L. Harper, Robert Stalnaker \& Glenn Pearce (eds.), Ifs: Conditionals, belief, decision, chance and time, 87-104. Dordrecht: Reidel. 


\title{
Conditional perfection
}

Wallis, John. 1687. Insitutio Logicae. Oxford: Amos Curteyne.

\author{
Elena Herburger \\ Georgetown University \\ Washington DC 200 \\ herburge@georgetown.edu
}

